\title{
Manufacturing in the 1990s-Productivity, Flexibility and Innovation
}

\author{
P. T. Bolwijn and T. Kumpe
}

\begin{abstract}
The article outlines the evolution of large multinationals as a result of the appearance of new market demands. Companies having to meet specific market demands, are shown to possess certain characteristics, related to the market demands concerned. The analysis shows that innovativeness will, in all probability, be the new market demand in the 1990s, in addition to the already existing ones of efficiency, quality and flexibility. Descriptions of ideal types illustrate the evolution of companies as they move from the Efficient Firm to the Quality Firm on to the Flexible Firm to, finally, the Innovative Firm. The phase model also includes the symptoms of crisis, when moving from one phase to another. Skipping phases appears to be difficult, if not impossible. The same holds true for moving to the next phase, while the organization has not finished with the preceding phase.
\end{abstract}

Industrial strategies for multinational producers have undergone profound changes over the past 10 years. The underlying causes are to be found in new market factors, technological developments and intensified competition. Changed market factors in particular served as a guideline in determining the direction of the new strategy, while new technologies and socio-technical renewal determined its contents. ${ }^{1}$

It is not likely that the 1990 s will bring quieter times. On the contrary, the impact of new technologies will become even greater, and there will be increasing competitive pressure through a truly common European market by 1992 and the rise of so-called 'fast industrializing countries' as SouthKorea, Taiwan, Mexico or, perhaps, Brazil and India. Just as is the case today, the prevailing market factors have a major influence in determining the industrial strategy of the 1990s.

P. T. Bolwijn is at Philips International, Eindhoven and University of Twente, and T. Kumpe is at Philips International, the Catholic University of Brabant and Zuidema Consultants.
Large companies often have little freedom of choice in determining their industrial strategy. Just as in the 1980 s they were forced to simultaneously fulfil performance criteria of efficiency, quality and flexibility, so in the 1990s these companies will have to translate the prevailing market factors into the pcrformance criteria required.

\section{Research Method}

We visited several outstanding companies in Europe, producing discrete products. We discussed their manufacturing strategy, did on-the-spot observations in their factories, and saw best manufacturing practices. We analysed the changes in market demands faced by these industries in the past decades as well as the changes in their structure and functioning associated with it.

The results are being presented as a contribution to model building. The model offers many opportunities for more systematic investigation. The insights obtained have proved already to be relevant for management.

\section{Evolution of Large-scale Industry}

\section{Increasing and Managing Mass Production}

For two centuries, until approximately 1960 , the history of industrialization was characterized by the pursuit of increased productivity. Aspects of this are the division of labour, mechanization and increased scale. The main effort was directed toward increasing and managing large-scale mass production. ${ }^{2}$

Until the 1960s, the market was characterized by the pursuit of quantitative growth. Demand outstripped supply and everything produced could be 
sold. In short, the market showed all the characteristics of a sellers' market. And although price was an important criterion for increasing turnover, price pressure was not great, witness the profit margins in the 1950s and the 1960s. These days have long since passed.

\section{The Rise of International Competition}

Competing under price pressure. The industrial environment quickly changed in the 1960 s, partly as a result of the preceding era of growth. The increasing scale of production could only be sustained by a corresponding growth in turnover. Companies, therefore, had to spread their wings across the world in the pursuit of larger markets. International trade flourished, also due to international trade agreements and the founding of the EEC.

A side effect of this growth in international trade flows, however, was an intensified competition on price as companies could produce in one country and sell their products throughout the world. This created a hitherto unknown pressure on prices, resulting in complete industries being moved to low-wage countries.

Price had become an important criterion for success in the market. Customers could (for the first time) select on price, comparing products made in various parts of the world. This drastically changed the nature of the efficiency approach. Restructuring, closing factories, transfering production to lowwage countries, processes of decreasing vertical integration, are completely different matters compared to the pursuit of improved working methods, increasing economies-of-scale and vertical integration, and increasing mechanizations in growth situations with full employment. Competing under conditions of increasing price pressure was new.

Competing under quality pressure. Competition changed again at the end of the 1960s. Increasingly affluent customers started to react against the nuisance of frequent breakdowns and costly, often timc-consuming, repairs of the poor products delivered by many a company. Customers started to select more critically and paid more attention to product quality. This was enhanced by Japanese industry which made a clear-cut strategic choice to bring out high quality, but sharply priced products. Quality now became an important factor for market success, in addition to price: companies had to compete on price and quality at the same time. ${ }^{3}$

The simultaneous use of price and quality as a competitive weapon was something new. Quality changed from a bottom-up, specialized approach based on more discipline and on testing and inspection, to a top-down approach directed at quality of the company as a whole. We will return to this later.

Competing under flexibility pressure. At the end of the 1970s the competitive struggle changed for the third time. In the meantime the market had turned from a sellers' market into a buyers' market in which production capacity exceeded demand. This was also one of the reasons for the changing market factors: the intensified international competition led many companies to look for new opportunities by widening the competitive battle in order to raise profitability. Japan, in particular, started to modernize its product lines more often e.g. new models of cars, engines and audio/video products were put onto the market at ever shorter intervals. Customers, confronted with a broad, often bewildering, array of products, reacted by becoming even more fashion-conscious.

Brand loyalty for many products all but disappeared and in addition to price and quality, choice from a wide product line with up-to-date designs increasingly became essential factors for market success. Internally this translated into increasing time pressure: turning out new products at a faster pace meant shortening development process time, as well as the time needed for engineering and pilot production runs.

Simultaneously competing on price, quality and assortment of products. This brings us to today's situation, in which cost, quality and choice have all three become important factors for market success. As a result, companies are under pressure to improve efficiency, quality and flexibility at the same time. ${ }^{+6}$

\section{The Phase Model}

\section{Relationships Between the Market Requirements}

The organizational characteristics belonging to efficiency, quality and flexibility in that order, appear to be interlinked. Companies, able to meet high quality requirements can be shown to 'naturally' develop from organizations, striving for efficiency. Similarly, flexible organizations spring forth from quality organizations.

Each new set of characteristics is an extension of the old one. The development of market requirements price, quality and assortment, corresponding to the characteristics efficiency, quality and flexibility can therefore be seen as an evolution where each new market requirement follows from its predecessor and enhances it.

When the price of a product became all important as a result of intensified international compctition, companies logically had to become extremely efficient.

The subsequent market requirement of quality arises now under these circumstances as a result of deliberate attempts by companies to widen the field of competition so as to ease price pressure and improve market position. This choice for quality 
(initiated by Japanese industry) stemmed not only from the idea that customers wanted good quality and were willing to pay for it. For years Deming and Juran had bcen hammering at the point that non-quality costs a lot of money, that quality improvement is ultimately the way to increased efficiency. Quality can therefore be seen as an extension of efficiency, encompassing and reinforcing it.

History repeats itself with the appearance of the new market requirement of wide ranges of up-to-date products. Flexibility, the ability needed to produce such product ranges, can only be achieved (at reasonable costs) if processes are controlled, if coordinated actions are taken, if components and semi-finished goods are of excellent quality with no rejects, returned lots or repairs wasting time and money; in short, if and when efficiency and in particular quality are properly under control. Flexibility is thus an extension of efficiency and quality. The last two characteristics are a precondition for the first one. Moreover, in the long term flexibility supports and enhances efficiency and quality. Flexibility is profitable since it leads to decimated inventories, less space needed, and simpler logistics; it improves quality through faster feedback loops, less inventories and improved overview of products and processes. Flexibility is all the more profitable as it enables companies to very quickly introduce new technologies-e.g. IC'sleading to high quality products with improved price/performance ratios. ${ }^{7.8}$

Companies now simultaneously compete on three fronts: the price of their products, their quality and the product line. Although these developments originate from industry, customer wishes remain very important and determine to a large extent the speed and success of the changes. Each new market requirement is an extension of the previous ones, in the sense that the corresponding organizational characteristics are an extension of each other. Thus, existing market requirements do not disappear when new ones come up, making the competitive game increasingly complex.

Now that the process has taken place this way, its evolution can be analysed and understood in retrospect. Based upon the insights obtained thereby, predictions can be made on which developments will, in all probability, take place in the 1990s.

\section{The Future Market Requirement}

Following through on our line of reasoning, the market requirement of the 1990s should now already be discernable as an extension of the existing ones; moreover it should lead to a further widening of the competitive battle. We may take it for granted that in the 1990 s the quality of products supplied by large companies, will be good. Poor products will then no longer exist. We can also assume that these companies by then will be able to quickly introduce improved products and offer a wide range of products.

In short, the large multinationals will have mastered the arts of quality and flexibility by then. Consequently, companies will be forced to really make their products stand out in the market. This can be done in various ways, for example by products with a clearly superior performance (the Volkswagen Beetle in the 1960s), or products with an individual style and price (Swatch watch), or completely new products (CD players in the 1980s, flat screen CTV's in the 1990s), or products opening up new markets (Walkman), or product-service combinations (large turn-key projects).

New technologies will often play a key role. The past decade has taught us the amazing possibilities new technologies offer for improving the performance of existing products and supplying even completely new products. Fibrc-optic cables, micro-electronics, industrial ceramics, micro lasers, highly accurate combined plastic-metal products are just a few examples. The use of new technologies in products accounts for much of the recent productivity increases. Other productivity improvements stem from advances in process-technologies, such as flexible manufacturing systems (FMS's), or automation equipment for placing surface mounted devices (SMD's).

The past decade also taught us, that technological know-how does not ensure success. Revivifying entrepreneurship, encompassing hands-on management, open communication, promoting and accepting new ideas, is an absolute necessity for a timely implementation of renewal. It calls, above all, for the courage to put existing procedures, conventions and strategies up for discussion. So it is not just a matter of technological expertise, although technologies do frequently play a major role.

The requirement of the 1990 s that products clearly stand out from those of competitors will be called uniqueness. The corresponding internal characteristics, needed to fulfil that requirement, we will call innovative ability, or innovativeness. The ability for renewal under time pressure will give innovativeness a completely new character, compared to the past.

It thus seems highly likely that innovative ability will be the new market requirement of the 1990s. If our previous arguments are correct, this requirement is an extension from the previous ones i.e. efficiency, quality and flexibility. Also, flexibility in particular should be mastered before innovative ability can be improved. This is true, for innovation always involves renewal, and rencwal always includes changc. Flcxibility mcans the ability to change quickly, innovativeness means the ability to renew quickly and thus more than change. It is quite possible to be flexible without being innovative, but 
the reverse is not true: you cannot be innovative without being flexible.

The former market requirements are not just a precondition for becoming innovative. As before, the new requirement reinforces the old oncs: innovativeness reinforces efficiency, quality and flcxibility. For it improves efficiency through better price/performance ratios of products, increases overall productivity (especially of white collar workers), it leads to improved quality and being able to more quickly capitalize new ideas enhances flexibility.

Summing up, the market requirements and performance criteria show an evolution in time, as given in Figure 1.

\section{The Phase Model}

The evolution of industrial performance criteria and corresponding market requirements described, are not only true for a few exceptional organizations, but they hold fairly generally for multinational producers of high volume and mass products. All these companies have passed through various stages of the same development.

As shown, companies having to fulfil specific performance critcria possess specific performance criteria and possess specific characteristics. Table 1 outlines the developments.

The table shows that during each period companies are mainly occupied with the markct requircment which emerged most recently. The periods can be seen as different phases over time. During each phase successful companies grow mainly by quickly and adequately responding to the market requirement which has appeared most recently. The developments lead to the following model depicting the evolution of large-scale industry (see Figure 2).

The above model shows the different phases of large companies from approximately 1960 until the 1990 s, in relation to changes in the environment.

Not only the characteristics of companies in a certain phase are interesting, but also the transition processes between the different phases. Gencrally speaking, transitions pass through the following stages:

(a) Denial of the new market demand. Extra efforts are being put into playing the old game. (It is not true. Give them more of the same.)

(b) The new markct demand is seen as a problem to be solved. (We have got a problem. Fix it boys!)

(c) The new market demand is seen as an opportunity to be exploited in the competitive battle. (This is great. Let us do it!)

Over the past years we have been able to see these transitions clearly in various industrial companies.

Of course, not all companies react with the same swiftness to a ncw, upcoming markct demand. Delay times vary. Also, new market demands do not emerge for all industrial sectors or product $/ \mathrm{mar}$ ket combinations at the same time. So not all parts of a company will be in the same phase of our model.

The following section will describe the ideal characteristics of companies during each phase.

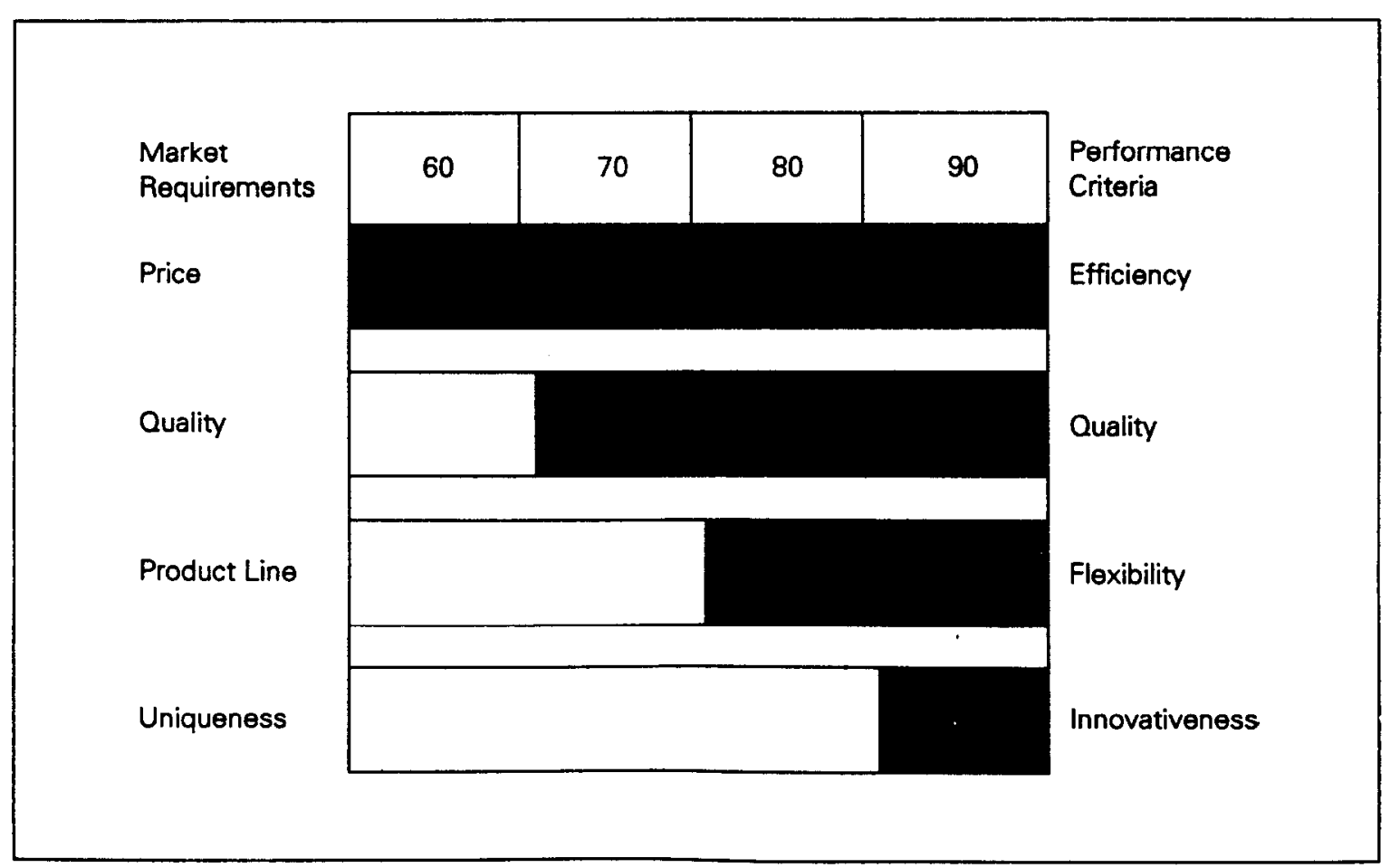

Figure 1. Evolution of market requirements and performance criteria for large manufacturing industry 
Table 1. Market requirements, performance criteria and ideal types of firms in the period 1960-2000

\begin{tabular}{|c|c|c|c|}
\hline & Market requirements & Performance criteria & Firm (ideal type) \\
\hline 1960 & Price & Efficiency & The efficient firm \\
\hline 1970 & Price, quality & Efficiency + quality & The quality firm \\
\hline 1980 & Price, quality, product line & Efficiency + quality + flexibility & The flexible firm \\
\hline 1990 & $\begin{array}{l}\text { Price, quality product line, } \\
\text { uniqueness }\end{array}$ & $\begin{array}{l}\text { Efficiency + quality + flexibility + } \\
\text { innovative ability }\end{array}$ & The innovative firm \\
\hline
\end{tabular}

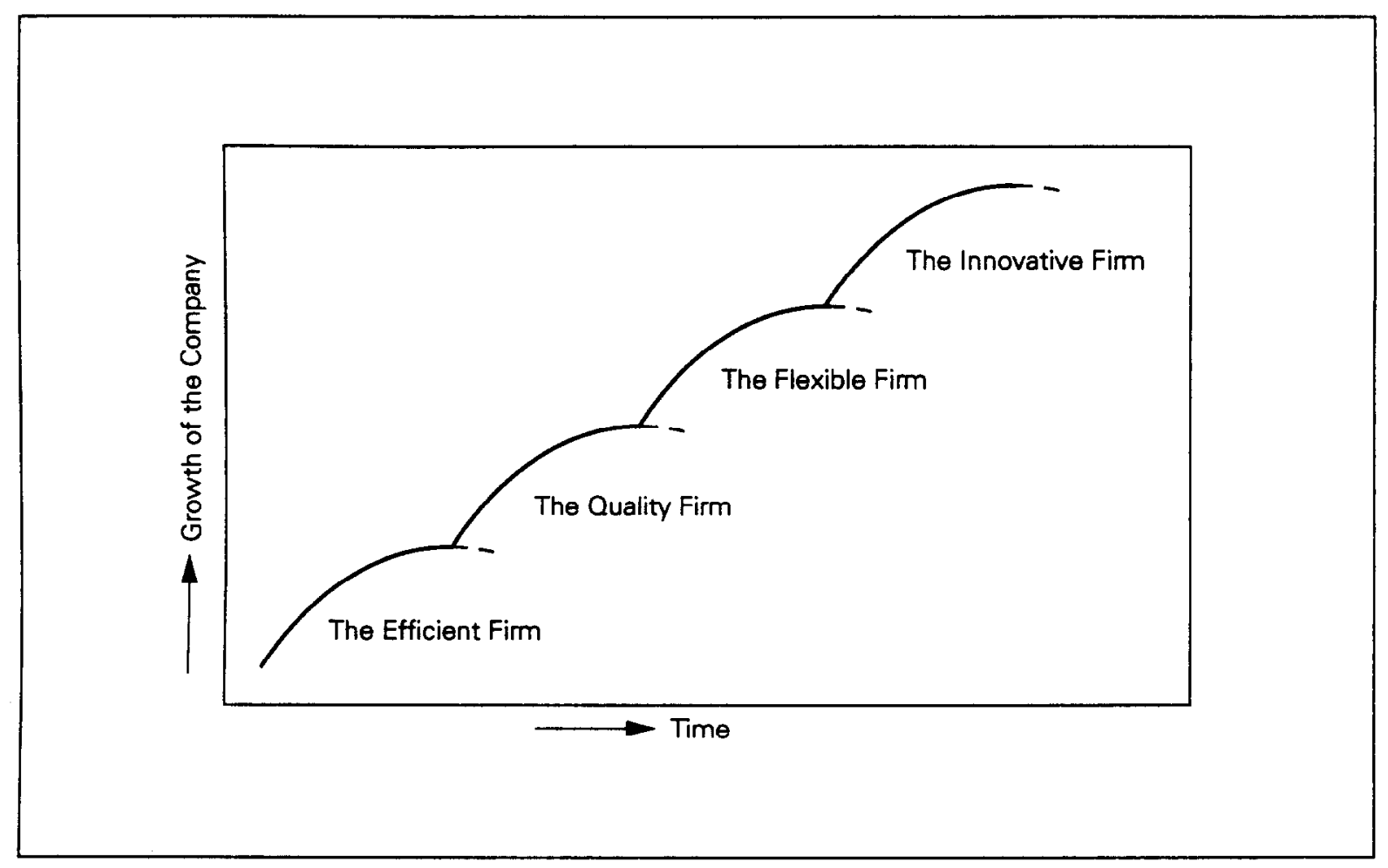

Figure 2. Evolution of high-volume manufacturing

In reality, companies or parts of companies will never show the 'pure' characteristics of one phase. The efficient firm or the flexible firm do not exist as such. Reality is therefore multiform. The hypothetical companies are described to obtain a clearcut picture of the characteristics of the various phases.

This gives an insight into where the main emphasis should be placed for each phase and what the success factors are for each phase. Moreover, it indicates what the transitions to the subsequent phase mean. This latter point is of vital importance for the effective management of the transition processes. A description of ideal types also clarifies our views on the requircd structure of our companies in the future, which in turn is vital for developing and implementing an effective industrial strategy for the long term.

One should, however, be aware that in theory more ideal types exist of the Efficient Firm, the Quality Firm, the Flexible Firm and the Innovative Firm. Indecd, using other premises leads to other ideal types. We described our premises with regard to markets, technology and competition in the introduction. Concerning peoplc and organization, we believe that people form the key element in effectively exploiting the possibilitics offered by new technologies. This more and more rules out force as a means of achieving the required improvement, change and renewal which are at the core of the Quality Firm, the Flexible Firm and the Innovative Firm, respectively.

The highly complex and uncertain environment leads to the search for ways to reduce risks and calls for competence overriding hicrarchy. But this must not lead to an approach in which organizations are seen as machines, where everything is programmable and decision making is completely rational. 


\section{The Four Phases and Their}

\section{Transitions}

\section{The Efficient Firm}

All efforts are directed at reducing costs in these companies: make it cheaper. The efficient firm produces a narrow range of products, tuned as it is towards the mass production of standard goods. It delivers competitively priced products of -in almost all cases-substandard quality, when measured to present-day quality levels. Organizational design is based on the creation of simple, repetitive tasks, deemed necessary for the production of fairly complex products using cheap labour. New technologies develop at a pace yielding ample time for $R \& D$ departments to devise new generations of products 'at leisure'.

The efficient firm separates line from staff, operation from control, planning from execution and individual jobs are split up to yield repetitive tasks. The aim is to run down the learning curve as fast as you can, both by the separation of jobs and by increasing scale. Within the growing organization, there is a mushrooming of ever more specialized staff functions.

Thus, growth is accompanied by, and made possible through, horizontal and vertical differentiation. The resulting complex organization is controlled efficiently by a multitude of rules, procedures and regulations. Managing is mainly planning and control. Nothing is left to chance and unforeseen events seldom, if ever, occur. The organization resembles a well-oiled, smoothly running machine.

\section{The Transition to Quality}

At the end of the 1960s the quality of products becomes increasingly important. The Japanese industry picks up the message of Deming and Juran. Japanese audio/video products, for instance, conquer the world not by means of lower prices, but by offering superior quality, at first noticed by such large customers as rental companies and hotel chains.

The efficient firms at first react with downright denials: "customers shop for bargains, not for quality'. They simply cannot believe it is (also) quality customers are after. So the efficient firms react to this new competition by intensifying the price war, the pursuit of efficiency is given new life.

Appropriate measures are taken everywhere to neutralize the new threat: more efficient designs in terms of factory costs, overhead valuc analyses to reduce overheads, drives to $\mathrm{rcv}$ up the asscmbly lines, purchasing campaigns to obtain cheaper supplies etc. These campaigns are successful insofar as costs are reduced and efficiency is raised significantly. But market shares do not increase, neither do profit margins. The new competitors are not losing the efficiency battle. On the contrary, their higherquality products conquer ever larger market shares.

Midway through the 1970 s almost all efficient firms recognize they have a quality problem. And, as with every problem, this can be solved in the scientific management way: responsibility for the problem is allocated to the experts designated, the quality department: 'Fix it, boys.' Since everybody 'knows' that quality costs money-you cannot have all the frills without the expense-optimum quality levels are calculated by comparing quality costs to benefits as reduced waste and less repair and service costs. Quality campaigns are started, mostly in the form of tightened discipline, more rules, procedures, testing and checking. The results are clear: the quality of products delivered improves considerably, but at high cost. On top of that, it becomes clear that any slackening of attention makes the quality levels slip. Quality is not really under control.

Slowly but surely it dawns upon western industry that quality should be seen as a powerful means of improving competitive strength. The quality threat turns into the quality challenge, to be met by all in the organization. The revival of Jaguar in the U.K., based largely upon a rigorous quality campaign, is a notable illustration of the quality message.

'Do it right the first time' is the new adage. Embedded into it is the recognition that all activities are part of a larger entity. All employees are, at the same time, customer as well as supplier. Top-down quality campaigns are started, aimed at improving the quality of everybody's work. Quality as well as quantity counts when assessing people's jobs. It is found that the organization can and must create specific conditions, necessary if people are to continuously improve the quality of their work.

Competence is a precondition for doing things right. Employees who, for whatever reason, are not suited to their task cannot raise the quality of their work to the required zero defects level.

Quality of management is particularly at issuc here, especially concerning professional expcrtise and leadership, without the hierarchical relationships being affected in the process. The top-down quality approach, often known by names as Total Quality Control or Company-Wide Quality Improvement, ultimately leads to a metamorphosis of the efficient firm, turning it into the quality firm.

\section{The Quality Firm}

All efforts are directed at the pursuit of quality as well as recognizing the still necessary efficiency improvements.

Quality is recognized as a strategic issue, for which top management's involvement and commitment are necessary. The whole of the company is involved in a long-term process of continuous 
improvement, encompassing products and processes, top management and factory workers. It is results that count, of course, and so concrete quality plans exist at all levels of the organization. Everybody is convinced there is money to be made through quality. Doing things right the first time is the best and cheapest way to run a business.

The many changes necessary to achieve this goal a mount to nothing less than a cultural shock for the efficient firm. Close co-ordination exists between product development and engineering, as well as between the technical and commercial sectors. Customer orientation, one of the specific characteristics of quality firms, is also based upon greatly improved information feedback systems, systematically collecting data from such varied sources as factories, competitors and customers. Flawless products through manufacturing perfection is at the heart of the firm. Design for manufacturing and building in quality right from the start of development, ensure a minimum of engineering changes and a maximum of manufacturing quality.

Within production, the all too well-known hectic pace of the efficiency period has given way to an efficient, but not too fast, smoothly running process, enabling people to inspect and test their work.

Dedication and precision, so necessary for achieving perfection, calls for motivated employees, ruling out non-functional hierarchical differences and letting businesslike actions prevail over politics. There is a spirit of co-operation, in which people are assessed on results and much attention is paid to horizontal and vertical communication.

Negative sanctions have largely given way to positive ones, getting people to really put their hearts into their work. The spirit of quality which permeates the firm, also extends to its suppliers. As for customers, 'The customer is always right' simply is not up for discussion any more. So the prime parking spaces are for customers, and satisfying a customer is really more important than pleasing the boss.

\section{The Transition to Flexibility}

In the mid-1970s a trend emerges towards significantly raising the variety of products, together with a reduction of their commercial life cycles. People are more fashion-conscious, faddish young customers demand up-to-date products incorporating the latest gadgets-e.g. Dolby $\mathrm{C}$ or dual cassette decks. However, at the beginning of the 1980 s this trend is seriously being questioned. Product variety apparently has got out of hand, leading to significant inefficiencies: factories are strained by having to produce too many models, logistic costs are on the rise, finished goods stocks are too high, and dumping obsolete models is a costly affair, driving prices downward.
All this results in campaigns to limit product diversity. These campaigns receive an extra impulse as analyses show that a sizeable number of products only account for a small proportion of sales and profits. On top of that, customer tastes do not seem to differ very much from each other, one and the same product can be sold successfully throughout the world to the global customer. Put differently: we do not need all this variety, all that customers want are low-priced quality products. So give them less choice, but pay even more attention to quality and price.

The restriction of product diversity does result in improved efficiency, as many products are found to add more to costs than to profits. Profit margins scarcely increase, however, prevented by the existing over-capacity in total world production. Moreover, products having a large market share need a wide assortment of models for so-called flank protection. There is also increasing evidence that the global customer does not exist, that markets are to be viewed as consisting of many niches. Finally, customer tastes keep changing in a fickle, unpredictable pattern.

So, it turns out to be an impossible task to stick to a restricted product line, pressures to react to ever more fragmented markets are simply too high.

More and more analyses show the lack of flexibility of the primary process being a problem. In some cases, for instance, reducing inventories - as part of logistic campaigns - leads to considerable loss of sales as products in high demand are sold out and cannot be replenished in time, while at the same time unduly large stocks exist of products not selling well. Also, long manufacturing lead times with the associated high inventories scriously hinder the necessary quality improvements and are costly. Development processes taking too long also have increasingly unfavourable effects: the shortening commercial life of products means that delays in introducing new products cause profits to nosedive.

In short, the lack of flexibility is seen as a problem. This is all the more so as conviction mounts that profit margins will remain low-due to overcapacity - and improved profitability will have to come from increased capital turnover rates. The solution is found in promoting flexibility by minimizing resetting times, setting up continuous flow productions with synchronized cycle times, introducing vastly improved product designs incorporating far fewer components etc. Development lead times are also analysed; parallel development, CAD equipment, project management, better coordination betwecn development and production are all used to speed up development processes.

The results are truly impressive. Within manufacturing, it is found that throughput times can be decimated, with proportional decreases in inventor- 
ies and space required. The associated fast feedback systems also greatly improve quality. Similar effects can be seen in development processes. But gradually it turns out that further improvements in flexibility involve more than methods and techniques as it demands a completely different way of 'looking' at the organization. This shows, for instance, in the changes necessary with regard to intercompany networks, customer-supplier relationships and the subject of vertical integration.

Regarding customer-supplier relationships, it is found that the introduction of continuous flow production in assembly results in similar requirements to be met by the parts manufacturers. Put differently, flexible assembly in combination with inflexible suppliers merely leads to shifting stocks away from the assembler to the suppliers. Because the production methods of the suppliers should be tuned to the requirements of the customer, lasting and intensive customer-supplier relationships are found to be necessary which are no longer based simply on price and quality. The short development throughput times call for better communication and co-operation all along the product line from components to final assembly.

While there is a trend towards buying more and more standard components from outside suppliers, high-tech components are increasingly seen as being of strategic value, necessary to be produced in house. As such, a high degree of vertical integration is deemed necessary for having technological leadership.

In order to be able to capitalize on flexibility, a topdown approach to flexibility is needed Such an approach opens the way to making flexibility profitable as the company becomes a market leader. And in the hotly contended markets, with products having very short commercial lives indeed, there is in fact little future for market followers. A broad, up-to-date product line is now used as a competitive weapon; with corresponding short delivery times and the ability to cater to the specific requirements of large customers.

In the 1980s, most industries have dramatically increased their assortment. In the U.S. auto branch, for instance, there are now more than 350 different models on sale, 50 per cent more than in 1984 and today's choice in cameras, audio/video products or motorcycles is simply bewildering (The Economist, 1 July 1989).

Companies are growing into the flexible firm.

\section{The Flexible Firm}

In addition to cost reduction and quality improvement, efforts are directed at increasing spccd: minimize the time needed from 'ore to customer store'. This also holds true for developing and introducing new generations of products. The flexible firm offers a wide and varied assortment of products, suiting the individualization trend of the affluent clientele. As said before, increased competition under circumstances of stagnating cconomies with the associated overcapacity leaves the Flexible Firm no alternative. The firm has a strong external orientation, keeping in close contacts with external developments in such areas as technologies, competition and markets.

The organizational design is based upon the creation of fast feedback loops, enabling processes to quickly react to changes, while retaining their reliability. The functional organization of the former efficient and quality firms has largely given way to product oriented organizations, consisting of relatively autonomous product-market combinations, business units, in which all primary and directly supporting functions arc present. Communication lines are therefore short, the number of hierarchical levels is limited and central staff groups are kept to a minimum.

Short manufacturing throughput times are achieved by continuous flow production of very small batches using, among others, synchronized cycle times and short resetting times. Both dedicated and mixed-model production lines are used, depending upon the turnover of the various models produced. The infamous logistic problems have been solved by now and goods flows are under control.

Most manual work is carried out in groups, employing multi-skilled cmployccs, responsible for day-to-day operations. The inflexible mechanizations of the past have given way to flexible, often computer-aided, automation.

Reducing the number of parts and components, designing families of products using standardized subassemblies and the introduction of CAD/CAM equipment all helped in speeding up the introduction of new products.

At all levels extensive use is made of temporary groups, such as task forces and problem-solving teams, to deal with unforeseen events. This contributes to a climate within which changes are regarded as a challenge.

\section{The Transition to Innovativeness}

The ever decreasing commercial life cycle of products poses a serious problem as the costs of the associated necessary technological innovations are rising steeply, often exceeding the financial resources of individual firms. Sharing costs is of course a natural solution, leading to a mushrooming of co-operative networks in research and innovation projects. Efforts to improve R \& D efficiency are also intensified.

But the effects of more innovation involve more than just higher $\mathrm{R} \& \mathrm{D}$ costs. The constant stream 
of new products sometimes bewilders customers, inducing a cautious wait-and-see attitude negatively affecting sales. Furthermore, new products may call for considerable changes in related areas: high definition television sets, for instance, require modified TV transmission stations. Working out the necessary new TV standards and modifying the existing transmitters is a complex, time-consuming process. Introducing new products might also conflict with existing products just reaching the cash-cow stage, thereby causing considerable problems with regard to profitability. Finally, innovative products, requiring new or drastically changed production processes, can mean considerable desinvestments in existing equipment.

As a result, companies attempt to play for time with new products, or to reach agreements on the time of introduction. In short, the new market demand is denied. However, there is growing evidence thatin the environment of structural overcapacity and tough competition from low-wage countries with an industrious highly educated populationinnovation is the key to achieving the required increases in productivity as well as improving market position.

New materials and components, new designs, new project organizations or new intercompany networks lead to great leaps forward in price/performance ratio's. Recent illustrations of such breakthroughs include the RISC processor design, Team Taurus development project approach, Megabit project, continuous flow production.

At first, innovation is promoted bottom-up by means of innovation teams, parallel development, introducing CAD and office automation equipment. In other words, the innovativeness of the organization is improved by speeding up the innovation processes without changing the organization's structure and culture.

There are a number of reasons why this is not possible. Major innovations more often than not involve radical changes, which are resisted by the existing organization. Creativity is also often stymied by the various layers of management, leading to a drying out of the stream of new ideas. It is also found that innovation, based upon creative ideas, contains a contradiction.

On the one hand the creation of an innovative climate requires openness, leaving scope for the imagination, while on the other hand innovation must be strictly controlled. Creative pcople are not always easy to get on with, are sometimes inclined to condemn the ideas of others. On top of that, it is absolutely essential to be able to estimate the side effects of all sorts of innovations. Promoters of new ideas seldom have an eye for the effects their plans will have on others. Finally, it turns out that there are gencrally more ideas than money.
In short, in order to be able to use innovation as a competitive weapon-to be more innovative than your competitors-a top-down approach is found to be necessary, involving mainly:

accelerating processes of renewal;

creating an innovative climate;

being able to closely manage creativity.

Mastering these processes changes the company into the innovative firm, of which many characteristics are described in the literature.

\section{The Innovative Firm}

In describing the characteristics of the innovative firm we use our own ideas as well as several articles on innovation. ${ }^{y-21}$

Cost reduction, quality improvement and increasing flexibility are all embedded in a continuous search for breakthroughs in all areas involved; with the ultimate goal of delivering outstanding products in terms of price, quality and performance. As such, the company of the 1990 s produces not only a wide and varied product range, but it is also known for its unique products.

The innovative firm is characterized by its ability to co-ordinate technological developments, applicable in separate business units. This means that the Strategic Management of Technology, as it is called, is an important activity. Outwitting competitors by changing the game, is an important part of the company's success.

Considerable use is made of multi-disciplinary ad hoc teams, generally manned by experts coming from all over the company. Lines of command to the various teams change with time, depending upon the state of the activities concerned. Integrating managers exist to direct and co-ordinate the various activities both horizontally-from research through development and engineering to production-as well as vertically along the product axis from components to end-products. The traditional linestaff distinction has lost most of its significance as teamwork is the name of the game.

The company firmly believes that -as the technological abilities of companies equalize - innovative capacity becomes the key success factor. Thus the basic premise is the inseparable link between technological innovation and social renewal. An innovative climate is created and maintained by such measures as the employment of mavericks, the use of an open-door policy, including the possibilities of hierarchical bypasses and the promotion of diagonal communication, supplementing the horizontal and vertical communication of the flexible firm. The innovative organization is a 'learning' organization. Open relations are maintained with the outside world. 
As innovation is not restricted to new technologies, the results of creativity are not limited to the introduction of new products. They also lead to novel approaches in opening up new markets, setting up new organizations-e.g. skunkworks, greenhouses, new ventures-designing new factories and offices, updating industrial relations and formulating new missions.

The know-how of people determines their contribution rather than their position. As so much value is placed upon know-how, there is a dual career line-one in management and a scientific onewhich to a large extent eliminates the tension between hierarchy and expertise. Status symbols have also been eliminated to a great extent. The innovative firm thus succeeds in using the knowledge and expertise of all its employees. This makes participation and human resource management more than an empty slogan. Coming up with alternatives-a necessary ingredient for an innovative organization-is encouraged through an informal, open atmosphere. Strong cohesion between all members of the organization and much attention to superordinate goals and the mission of the company makes for the concerted, aggressive approach that makes the company such a formidable competitor. More often than not, successful innovations can be applied in various parts of the organization, hence much time and energy is spent in spreading the word.

All this does not mean that all of the company is in a continuous state of flux. On the contrary, the Innovative Firm has to strike the right balance between renewal and stability; the same holds true for the balance between entrepreneurship and the tight, hands-on management of innovation. Therefore, within the company various organizational forms exist alongside one another, depending upon the requirements of the specific activities concerned.

Just as not all of the organization is in a process of innovation, not all of the company's products are unique. It simply puts more innovation into more products, apart from producing a wide variety of products, comparable to those of competitors. That keeps it one step ahead of competition.

\section{Managing the Evolution Process}

\section{Skipping Phases}

The speed of the evolution described, is not determined by individual companies, but is the outcome of a complex entity of external events. Chances are, therefore, that companies are still engaged in mastering a certain phase, while the next phase has already emerged. This may lead to a situation where a company tries to skip a phase, or starts on the next phase while still heavily involved in the transition from the previous phase.
It is very doubtful whether this is possible, in view of the relationships and dependencies existing between the various performance criteria. The observation that fulfilling previous criteria is a necessary precondition for the ability to control the following criterion in fact rules out the possibility of skipping phases.

At this moment the industrial world is in a transition to flexibility. A number of companies are, however, still engaged in mastering quality. This results in a number of predictable problems. It is certainly possible to promote flexibility without quality - in the sense of total quality-being completely absorbed by the company. This can be done by such actions as shortening manufacturing throughput times or setting up flow productions. More flexibility can also be achieved by improved logistics, including the elimination of intermediate warehouses. Also in the development and engincering processes setting up project teams, introducing CAD equipment or using Design for Assembly can lead to reduced development lead times and hence increase flexibility.

All these methods will certainly increase the flexibility of a company and lead to considerable cost savings as inventory levels are slashed and the amount of space required-both for storage and manufacturing processes-is considerably reduced.

However, capitalizing on flexibility by using it as a competitive wcapon, will be virtually impossible if the company is not enough of a quality firm. Capitalization means the company is expanding its product line, with faster responses to changing customer requirements and with more segmentation of the markets. Then it will turn out that the lack of quality means that expanding product lines and all those other measures have the effect of increasing costs. Such cost increases may show up anywhere, simply because the lack of quality can show up anywhere. For example, expanding product lines may result in sharply increasing stocks because co-makership relations have not been introduced properly. It may also lead to a considerable increase of production start-up costs as well as lost productive hours because of inadequate design quality.

It may show that the reduction of commercial life cycles and the expansion of product lines cannot get off the ground because development throughput times are increased, because design for assembly is not used, because the management decision-making processes take too long or because specifications are constantly changing.

In short, capitalizing on flexibility, becoming a flexible firm, requires 'Quality in all aspects of the business'. Without this level of quality, processes are delayed. Compensating for those delays is difficult and expensive. Thus, companies which are not far 
enough along the path toward total quality claim that flexibility costs money, that (global) customers have the same tastes and demands all over the world.

The fragmentation of markets is already under way and companies will find that flexibility i.e. the capitalization of flexibility, will ultimately lead to incrcascd profitability. Of course, the concept of flexibility should be handled prudently. Product designs should be such that diversity can be built in at the end of the production process. A wide product line should not be constructed in such a way that it requires a broad spectrum of very expensive moulds or special tools. Designers, developers and engineers should be closely linked with the production process. That, of course, is again a typical characteristic of total quality.

The same holds true for the necessary customer orientation. Henry Ford's saying: 'They (the customers) can have any colour as long as it is black' is often quoted as an illustration of how little customer-oriented Ford was in those days. However, take a look at the audio equipment on offer in 1987 and you will notice that you can have any colour, as long as it is black.

It is a safe bet that at the beginning of the 1990s, the quality of products supplicd by large multinationals will be good. By then the quality message has been brought home. It should be clear that fierce international competition will then force companies to distinguish their products from those of their competitors. This can be achieved by completely individual styling, but this has in general a very short-lived cffect because successful styling is quickly copied.

Multinationals who want their product families to have a large share of the major world markets will then have no option but to distinguish themselves from their competitors by means of flexibility. They offer their customers shorter delivery times, with an increasing number of possibilitics for ordering at short notice. They supply products in individual styling or in styling required by specific customers. They supply a choice as large as possible with regard to product line, price, design and styling. The company that can do this has created the conditions for the following phase, the expansion of the innovative ability of the company.

So, skipping a phase is impossible. What can be done is learning by doing. The conditional relationship between efficiency, quality, flexibility and innovativeness makes it possible to utilize learning effects.

\section{$A$ Process of Learning}

There is a certain degree of logic in the evolution. Organizations can only achieve the characteristics belonging to a certain phase once they have achieved the characteristics of the preceeding phases.
The main outline is as follows:

$\begin{array}{ccc}\text { Efficient Firm } & : & \text { specialization and hierarchization } \\ \downarrow & \downarrow \\ \text { Quality Firm } & : & \text { communication and co-operation } \\ \downarrow & \downarrow & \downarrow \\ \text { Flexible Firm } & : & \text { integration and decentralization } \\ \downarrow & \downarrow \\ \text { Innovative Firm : } & \text { participation and democratization }\end{array}$

This shows, already, that the emphasis is on structure and culture alternatively.

Although each phase differs considerably from the previous ones, the strengths developed in each phase not only are retained during the evolutionary process, but newly acquired capabilities contain the previous ones and reinforce them. The evolution can therefore be seen as a process of learning.

Co-operation and communication, for example, which are characteristics of the quality firm, are retained in the flexible firm. Even more important, the integration and decentralization of the flexible firm only lead to success because of the good cooperation and communication obtained previously.

By close observation we may discover many achievements that overlap and reinforce one another, and that can be utilized as a learning effect. We will describe that elsewhere.

\section{Planning the Changes}

In the 1990 s multinationals will have to simultancously fulfil the requirements of efficiency, quality, flexibility and innovation as they will be competing on four fronts: price, quality, assortment and uniqueness of their products. Ideally speaking, the successful world-sized company will then be an innovative firm. Based upon our arguments, much can be said about the change processes on the way to that innovative company.

One must be aware, however, that in reality each company is a mixture of the ideal types outlined. The various parts, such as business units or article groups, will not all be in the same phase of our growth model. This is because market requirements have not evolved to the same extent or because the processes of adjustment and change take place differently.

Identifying the phenomena belonging to the transition stages (denial-threat-challenge) is very uscful in drawing up and planning the changes required. Such improvement plans should include indentifiable actions aimed at each criterion: efficiency, quality, flexibility and innovation separatcly, taking into account the relative importance of each criterion in time. The evolution in time for the various criteria and the rcalization that skipping phases is next to impossible, yield the main instruments for co-ordination of the various plans. 
Maximum use should be made of the learning effects.

It needs no explanation that management plays a pivotal role on the way towards the innovative firm. Exploring the external developments underlying the speed and extent of the moves from efficiency to quality, on to flexibility and finally, innovation serves as an important tool of management here. Doing this i.e. analysing the basics of both the internal as well as the external changes going on, an increase of uncertainty, complexity, interdependancy and individualization is revealed. Each of these makes for specific demands being placed on management. The results of this analysis will be published elsewhere.

\section{Relationships with Other Models}

In the literature, various growth models and development models are described. They differ from our model on several points.

Greiner ${ }^{22}$ describes the growth phases of a company, without taking account of the environment. The company is thus implicitly conceived as closed or the environment is assumed to be stable, which is understandable concerning the market in the beginning of the 1970s. Greiner also describes the transition phenomena between the phase transitions; he calls these crises.

In various contingency approaches it is stated that structure and functioning of organizations should be consistent with the environment. In the case of Perrow, ${ }^{23}$ for example, this results in four types of organizations depending on two environmental variables: complexity (simple vs complex) and stability (stable vs dynamic).

Mintzberg ${ }^{24}$ draws up a typology of organizational structures and also establishes links with the environment in the above terms. The configurations are built up by describing in particular the most important structural elements and co-ordination mechanisms.

This results in five ideal types i.e. simple structure, machine bureaucracy, divisionalized form and adhocracy, each with its own co-ordination mechanism. Mintzberg describes in detail the functioning of these types.

In agreement with others, Mintzberg shows that the size and age of an organization forms an essential element, leading organizations to expand from simple structure into a machine bureaucracy, which again grows into a divisionalized form, irrespective of the environment. Based upon changes in the environment, Mintzberg says that the simple structure and the machine bureaucracy are structures of yesterday, the professional bureauracy and divional- ized form are structures of today, while adhocracy is the structure of tomorrow. The latter must be innovative and, according to Mintzberg, is typically young.

Our efficient firm is identical to Mintzberg's machine bureaucracy, while the innovative firm is closely related to adhocracy. Our quality firm and flexible firm can be regarded as the stage after machine bureaucracy and the stage before adhocracy, respectively. New elements of our approach are the sequential development of market requirements, the crucial role they play in determining a company's success, and the strong interrelations between the performance criteria.

The efficient firm and the quality firm are both bureaucratic organizations, whereas this is not true of the flexible firm and the innovative firm. This distinction is described in detail by Burns and Stalker ${ }^{9}$ in terms of mechanistic and organic systems. They show that managing innovations requires organic systems.

Toffler ${ }^{25}$ describes a non-bureaurcratic organization which is very similar to our Flexible Firm. He too calls the organization of the future an adhocracy in which bureaucratic hierarchies have been removed.

Porter ${ }^{26}$ outlines three possible strategies from which companies have to choose in order to stand out from their competitors i.e. pricing, differentiation and focusing. Pricing means a strategy of cost cutting, establishing overall cost leadership, so as to enable companies to offer the lowest priced products in a certain market segment. Differentiation has to do with trying to offer unique products, uniqueness showing in quality, design, technology, product mix or whatever other aspect possible. Customer tastes and wishes often play a major role here. Focusing is a strategy through which companies limit their scope to a certain market segment or to a narrow product range. Within that scope, a strategy of pricing or differentiation is followed.

We agree with Porter that companies should stand out from their competitors. Wc also agree on the importance of customer demands. We differ with Porter, however, in our stating that several market demands must be met simultancously. The time phasing of the market factors and their interrelationships, are new elements.

This holds especially for our statement that quality, flexibility and innovation can be pursued in such a way that they enhance one another and, at the same time, improve the efficiency.

Miller's research, ${ }^{27}$ based upon studying hundreds of large and medium-sized Western companies, shows the relations between strategy, structure and environment. Different from Porter, he distinguishes four strategies which are not mutually exclusive. 
These strategies focus on costs, differentiation, width of product assortment (niche vs diversification) and product innovation respectively. His rescarch indicates that the various strategies followed often coincide with a stable (costs), hostile (differentiation), heterogeneous (assortment) or dynamic (innovation) environment. The environmental characteristics have some elements in common with our market demands: efficiency, quality, flexibility and innovativety. Concerning structure, Miller uses some tens of variables, divided into bureaucreatic and organic ones. The first two strategies of costs and differentiation corrolate with a bureaucratic structure, whereas the other two strategies need an organic structure. The relationships between strategy, structure and environment as found by Miller, support our arguments. But Miller's study does not contain the time sequence in the environmental changes. As a consequence he does not mention a phased evolution and the associated learning processes within organizations.

Finally, in addition to the previously mentioned contingency factors, Child ${ }^{28}$ points to the significance of 'political contingency'. This is used to mean in particular the norms, values and skills of management and technical experts which determine the choices which are made with regard to the structure and functioning of the organization. Mintzberg speaks in this connection of the influence of power, fashion and culture. Our description of ideal types in a growth model based on explicit 'political' assumptions thus corresponds in this respect with the Child and Mintzberg model.

\section{Conclusions}

All told, we can draw the following conclusions:

(a) Success or failure in the 1990 s will be determined by the company's innovative ability.

(b) Competing in the 1990 s will mean to simultancously compete on the four fronts: efficiency, quality, flexibility and innovation.

(c) Quality, flexibility and innovation, when fully mastered, all enhance productivity.

(d) Quality is a necessary precondition for flexibility, and flexibility neessarily precedes innovation. Put differently: without total quality (of the 1970s), companies will not meet the flexibility requirements of the $1980 \mathrm{~s}$. And without the art of flexibility, a company cannot really become innovative.

(c) From the 1960s to the 1990s large companies undergo an evolution, which can be separated into four phases, stressing efficiency, quality, flexibility and innovation consecutively.

(f) It is difficult, if not impossible, to skip a phase.

(g) Each transition of phases shows specific characteristics. (h) During the process of evolution, structural changes take turns with cultural changes.

(i) As a company in each phase builds upon the strengths developed in preceding phases, the evolution can be seen as a process of learning.

It is essential that management understands that there are no 'natural' conflicts between efficiency, quality, flexibility and innovation. So today it is not a matter of choosing between positions of low-cost producer, quality producer or flexible producer. Multinationals today should be flexible, low-cost quality producers. And in the 1990 s, add innovation as well.

Multinationals therefore face increasingly complex market demands. It is the management challenge to build companies that can meet these seemingly contradictory demands.

Acknowledgement-The authors thank all those who commented on earlier drafts of this article. Their suggestions and improvements have been of great help. This article is based on a presentation at the 2 nd International Production Management Conference on Management and New Production Systems at Fontainebleau in March 1989.

\section{References}

(1) P. T. Bolwijn, J. Boorsma, Q. H. van Breukelen, S. Brinkman and T. Kumpe, Flexible Manufacturing: Integrating Technological and Social Innovation. Elsevier Science Publishers (1986).

(2) William J. Abernathy and Kenneth Wayne, Limits of the learning curve, Harvard Business Review, p. 109, September/October (1974).

(3) Armand V. Feigenbaum, Total quality leadership, Quality for Better Product Assurance and Reliability, 25, p. 18 (1986).

(4) T. Kumpe and P. T. Bolwijn, Automation Without Tears. Proc. 2nd Int. Conf. on Flexible Manufacturing Systems, p. 391, London (1983).

(5) P. T. Bolwijn and T. Kumpe, Toward the flexible factory, The McKinsey Quarterly, p. 40, Spring (1986).

(6) Arnoud De Meyer, Jinichiro Nakane, Jeffrey G. Miller and Kasra Ferdows, Flexibility: the next competitive battle, the manufacturing futures survey, Strategic Management Journal, 10, p. 135 (1989)

(7) P. T. Bolwijn, C. J. van Ham and T. Kumpe, Industria/ Strategy of the 1980s, Paper presented at the Business Week's Fifth Annual European Corporate Planning Conference, London, 18-19 October (1983).

(8) Kasra Ferdows and Wickham Skinner, The sweeping revolution in manufacturing, $J$. of Business Strategy, 8 (2), 64-69, Fall (1987).

(9) Tom Burns and G. M. Stalker, The Management of Innovation. Tavistock (1968)

(10) Peter F. Drucker, The discipline of innovation, Harvard Business Review, p. 67, May/June (1985).

(11) Joseph Finkelstein and David Newman, The third industrial revolution: a special challenge to managers, Organizational Dynamics, p. 53, Summer (1984).

(12) Eli Ginzberg and George Vojta, Beyond Human Scale: The Large Corporation at Risk, Basic Books (1985). 
(13) Frederick W. Gluck, Big-bang management: creative innovation, The McKinsey Quarterly, p. 49, Spring (1985).

(14) Quincy J. Hunsicker, Innovation and renewal: a European perspective, The McKinsey Quarter/y, p. 61, Spring (1984),

(15) Ted Kumpe and Piet Bolwijn, Manufacturing: the new case for vertical integration. Harvard Business Review. p. 75. March/ April (1988)

(16) Raymond E. Miles and Charles C. Snow, Organizations: new concepts for new forms, California Management Review, XXVIII, p. 62, Spring (1986).

(17) Tom Peters, Thriving on Chaos: Handbook for a Management Revolution, Macmillan (1988).

(18) James Brian Quinn, Managing innovation: controlled chaos Harvard Business Review, p. 73, May/June (1985).

(19) Robert B. Reich, Entrepreneurship reconsidered: the team as hero, Harvard Business Review, p. 77, May/June (1987).

(20) Peter $M$. Senge. The new management: moving from invention to innovation, New Management, p. 6. Summer (1986).
(21) Michael Tusman and David Nadler, Organizing for innovation, California Management Review, XXVIII, p. 74, Spring (1986).

(22) Larry E. Greiner, Evolution and revolution as organizations grow, Harvard Business Review, p. 37, July/August (1972).

(23) Charles Perrow, A framework for the comparative analysis of organizations, American Sociological Review, 32, p. 194 (1967).

(24) Henry Mintzberg, The Structuring of Organizations, Prentice Hall (1979).

(25) Alvin Toffler, The Adaptive Corporation. McGrawhill (1970).

(26) Michael E. Porter, Competitive Advantage, Creating and Sustaining Superior Performance. The Free Press (1985).

(27) Danny Miller, The structural and environmental correlates of business strategy, Strategic Management Journal, 8 (55) (1987).

(28) John Child, Organizational structure, environment and performance: the role of strategic choice, Sociology, p. 1 (1972). Also: Organization, A Guide to Problems and Practice. Harper \& Row (1986). 